\title{
Fluvoxamine: A Review of Its Mechanism of Action and Its Role in COVID-19
}

\author{
Vikas P. Sukhatme ${ }^{1 *}$, Angela M. Reiersen ${ }^{2}$, Sharat J. Vayttaden ${ }^{3}$ and Vidula V. Sukhatme ${ }^{4,5}$ \\ ${ }^{1}$ Department of Medicine and the Morningside Center for Innovative and Affordable Medicine, School of Medicine, Emory \\ University, Atlanta, GA, United States, ${ }^{2}$ Department of Psychiatry, School of Medicine, Washington University in St. Louis, St. \\ Louis, MO, United States, ${ }^{3}$ Independent Researcher, Montgomery Village, MD, United States, ${ }^{4}$ GlobalCures, Inc., Newton, MA, \\ United States, ${ }^{5}$ Department of Epidemiology, Rollins School of Public Health, Emory University, Atlanta, GA, United States
}

Fluvoxamine is a well-tolerated, widely available, inexpensive selective serotonin reuptake inhibitor that has been shown in a small, double-blind, placebo-controlled, randomized study to prevent clinical deterioration of patients with mild coronavirus disease 2019 (COVID-19). Fluvoxamine is also an agonist for the sigma-1 receptor, through which it controls inflammation. We review here a body of literature that shows important mechanisms of action of fluvoxamine and other SSRls that could play a role in COVID19 treatment. These effects include: reduction in platelet aggregation, decreased mast cell degranulation, interference with endolysosomal viral trafficking, regulation of inositolrequiring enzyme 1 $\alpha$-driven inflammation and increased melatonin levels, which collectively have a direct antiviral effect, regulate coagulopathy or mitigate cytokine storm, which are known hallmarks of severe COVID-19.

Keywords: SARS-CoV-2, cytokine storm, acute respiratory distress syndrome, interleukins, inflammation

\section{INTRODUCTION}

Initially used to treat obsessive-compulsive disorder (OCD), fluvoxamine (FLV) has been shown to have the strongest activity of all SSRIs at the sigma-1 receptor (S1R) with low-nanomolar affinity (Narita et al., 1996). FLV agonism on S1R potentiates nerve-growth factor (NGF)-induced neurite outgrowth in PC 12 cells (Nishimura et al., 2008; Ishima et al., 2014). S1R is a chaperone protein at the endoplasmic reticulum with anti-inflammatory properties (Ghareghani et al., 2017). FLV's antiinflammatory effects likely stem from its regulation of S1R, which modulates innate and adaptive immune responses (Szabo et al., 2014). S1R is also an important regulator of inositol-requiring enzyme 1a (IRE1)-driven inflammation (Rosen et al., 2019) (Figure 1).

FLV and other SSRIs regulate inflammatory cytokine activity and gene expression in both cell and animal models of inflammation (Taler et al., 2007; Tynan et al., 2012; Rafiee et al., 2016; Ghareghani et al., 2017; Naji Esfahani et al., 2019; Rosen et al., 2019). The potential of FLV to dampen cytokine storm has implications in COVID-19. COVID-19 severity is associated with an increased level of inflammatory mediators including cytokines and chemokines (Chen G. et al., 2020; Chen N. et al., 2020; Huang et al., 2020; Tay et al., 2020). Other S1R agonists like fluoxetine have been reported to have antiviral activity (Zuo et al., 2012; Bauer et al., 2019). These studies have raised interest in the potential therapeutic role of FLV and S1R agonists in COVID-19 (Vela, 2020; Hashimoto, 2021).

This review illustrates mechanisms of action underlying anti-inflammatory and antiviral properties of FLV. It covers preclinical studies on effects of FLV and S1R agonists on inflammation, and summarizes currently available clinical data for FLV treatment in COVID-19. 


\section{Fluvoxamine}

Potential repurposed drug candidate for COVID-19

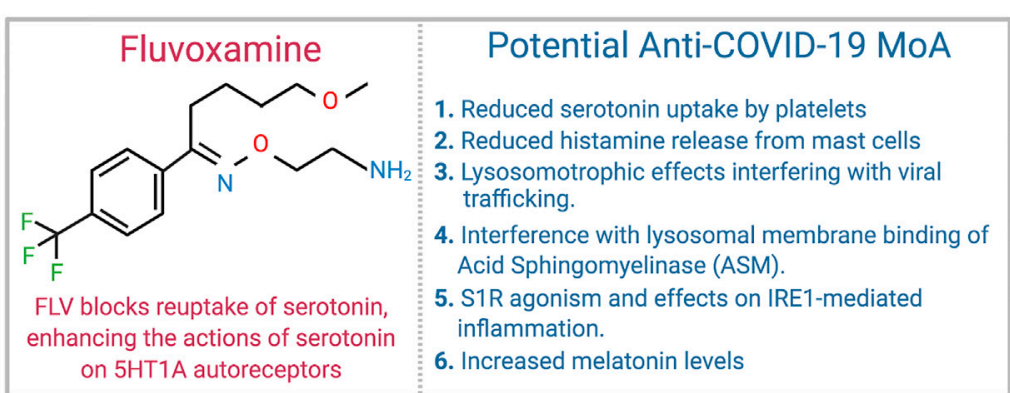

FLV reduces serotonin uptake by platelets
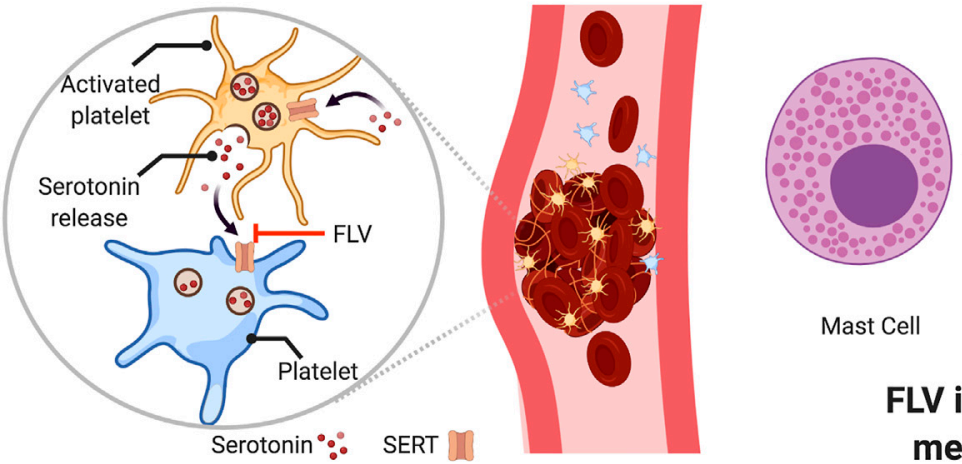

Mast Cell Activation from mast cells.

Mast Cell
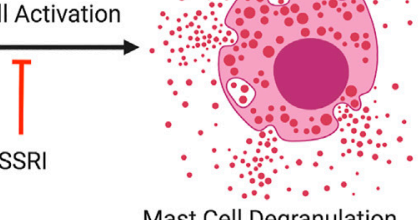

FLV interferes with lysosomal membrane binding of ASM

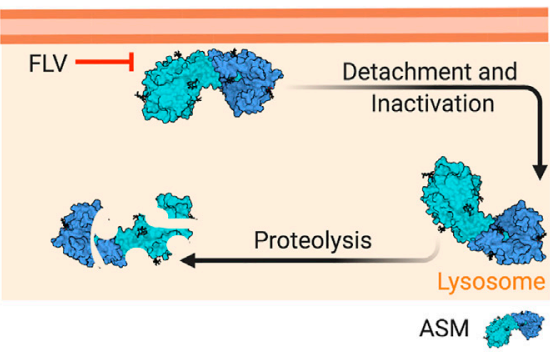

FLV activation of S1R inhibits IRE-1-mediated inflammation lysosomotropic

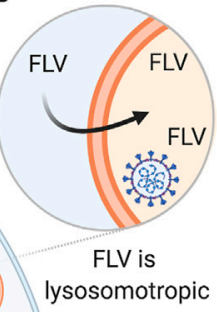

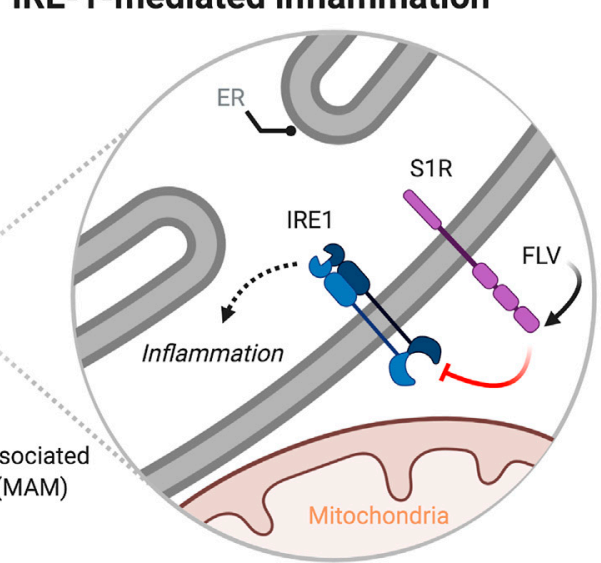

FIGURE 1 | Potential anti-COVID-19 mechanisms of action of fluvoxamine. Figure created using Biorender. 


\section{Indications for Fluvoxamine}

Fluvoxamine maleate is available as immediate release tablets and controlled-release capsules. FLV is indicated to treat obsessions and compulsions in patients with OCD. The half-life of FLV is 9-28 $\mathrm{h}$ depending on its formulation, and the recommended dosage is $100-300 \mathrm{mg} /$ day (FDA, 2012).

\section{ORIGINAL MECHANISM OF ACTION}

\section{Serotonin Transporter Inhibition}

FLV blocks reuptake of serotonin at the sodium-dependent serotonin transporter (SERT) of the neuronal membrane, enhancing actions of serotonin on 5HT1A autoreceptors (Dell'Osso et al., 2005; FDA, 2012). FLV has negligible affinity for $\alpha 1$-, $\alpha 2-, \beta$-adrenergic, muscarinic, dopamine D2, histamine H1, GABA-benzodiazepine, opiate, 5-HT1, or 5-HT2 receptors (Irons, 2005).

\section{LIKELY MECHANISMS OF ACTION IN COVID-19}

\section{Platelet Aggregation}

Platelets lack the enzyme to synthesize serotonin ( $\mathrm{Ni}$ and Watts, 2006). A SERT enables rapid uptake of serotonin from plasma (Vanhoutte, 1991). During thrombosis platelets release serotonin, facilitating hemostasis through platelet aggregation (Berger et al., 2009) (Figure 1), and promotes recruitment of neutrophils (Duerschmied et al., 2013). SSRIs can therefore increase bleeding time (Leung and Shore, 1996) or reduce serum serotonin by $>80 \%$ and reduce neutrophil recruitment (Duerschmied et al., 2013). Platelets from individuals treated with SSRIs, and platelets from SERT knockout mice, show decreased aggregation (Celada et al., 1992; Carneiro et al., 2008; McCloskey et al., 2008). Measures of coagulation and hemostasis were lower in patients with serotonergic antidepressant than in patients without serotonergic antidepressant (Geiser et al., 2011). A hyperserotonergic state distinguishes COVID-19 and non-COVID-19 acute respiratory distress syndrome, biochemically (Zaid et al., 2021) and clinically (Helms et al., 2020a; Helms et al., 2020b). This is likely pathologic across a multitude of organs (akin to serotonin syndrome, F. Jalali-personal observation and communication) and may originate from an immune-mediated (Althaus et al., 2020; Nazy et al., 2021) state of platelet hyperreactivity (Zaid et al., 2021), resulting in florid platelet degranulation of serotonin into plasma.

A concomitant impairment of serotonin reuptake may exacerbate this hyperserotonergic state. Serotonin clearance relies on a healthy pulmonary endothelium (Thomas and Vane, 1967; Joseph et al., 2013), that is injured in COVID-19 (Ackermann et al., 2020). Platelet serotonin liberation can be reduced with chronic or early de novo SSRI use (Cloutier et al., 2018), since SSRIs deplete serotonin content of platelets (Narayan et al., 1998; Javors et al., 2000). Initiation of de novo SSRIs at later stages of moderate to severe COVID-19, however, may be unpredictably harmful given the existing hyperserotonergic state (Zaid et al., 2021) unless counterbalanced by other beneficial effects of SSRIs. Indeed, direct serotonin antagonism specifically targeting the serotonin $2 \mathrm{~A}, \mathrm{~B}$ and $\mathrm{C}$ receptors with drugs such as cyproheptadine or mirtazapine in this stage may be beneficial and is being explored (F. Jalali-personal communication).

Three trials assessing benefit of anticoagulants to treat COVID-19 have paused enrollment of critically ill COVID-19 patients who require intensive care unit (ICU) support (NHLBI, 2020). Therapeutic blood thinners did not reduce need for ICU admission in this patient-group. Since full doses of therapeutic anticoagulants increase risk of internal bleeding, FLV could perhaps inhibit blood clotting more safely.

\section{Mast Cell Degranulation}

Human mast cells (MCs) are a viral reservoir for RNA viruses like HIV (Sundstrom et al., 2004). Retinoic acid-inducible geneI-like receptors of mast cells can detect RNA viruses (Fukuda et al., 2013). Viruses can cause degranulation of MCs in a Sphingosine-1-Phosphate (S1P) -dependent pathway (Wang et al., 2012). MCs express angiotensin converting enzyme 2 (ACE2), the principal receptor for SARS-CoV-2 entry into cells, thus defining a route by which MCs could become hosts for this virus (Theoharides, 2020). Post-mortem lung biopsies of COVID-19 patients have linked pulmonary edema and thromboses to activated MCs (Motta Junior et al., 2020). Antidepressants also decrease histamine release from MCs (Ferjan and Erjavec, 1996). SSRIs like fluoxetine decreased mRNA levels of protease-1 in MCs (Chen et al., 2008). Therefore, SSRIs like FLV could reduce cytokine storms in COVID-19 patients (Figure 1) because of atypical response of MCs to SARS-CoV-2.

\section{Lysosomotropism}

S1R agonists like FLV and fluoxetine are lysosomotropic (Hallifax and Houston, 2007; Kazmi et al., 2013). Fluvoxamine has a predicted pKa of 8.86 (DrugBank, 2005; Wishart et al., 2018) and is susceptible to protonation in the physiological $\mathrm{pH}$ range. Less polar, unionized form of basic drugs can easily cross membranes. Basic drugs like FLV can get protonated in the lysosome, which hinders the now-charged moieties from crossing membranes. $\beta$-coronaviruses, like SARS-CoV-2 and mouse hepatitis virus (MHV), use lysosomal trafficking to escape from infected cells (Ghosh et al., 2020) (Figure 1). GRP78/BIP, a chaperone that facilitates coronavirus infectivity (Chu et al., 2018; Ha et al., 2020), is co-released with $\beta$-coronaviruses through this pathway (Ghosh et al., 2020). The SARS-CoV open reading frame protein 3A (ORF3a) (Gordon et al., 2020) is a viroporin that localizes to lysosomes (Ghosh et al., 2020), disrupts their acidification (Yue et al., 2018), and contributes to viral egress (Lu et al., 2006; Castano-Rodriguez et al., 2018; Yue et al., 2018). Given the lysosomal egress of $\beta$-coronaviruses from infected cells, lysosomotropic drugs like FLV could have antiviral effects in the virus laden lysosomes (Homolak and Kodvanj, 2020) (Figure 1). 


\section{Acid Sphingomyelinase}

Lysosomotropic drugs displace acid sphingomyelinase (ASM) from lysosomal membranes leading to its degradation (Breiden and Sandhoff, 2019) (Figure 1). Treatment of mice with S1R agonists like fluoxetine (Hashimoto, 2015) reduces both acid sphingomyelinase activity and protein levels in neurons (Gulbins et al., 2013). This is consistent with partial proteolysis of acid sphingomyelinase by fluoxetine (Kornhuber et al., 2008). Fluoxetine can efficiently inhibit entry and propagation of SARSCoV-2 in Vero-E6 cell lines (Schloer et al., 2020). It also exerts antiviral activity against influenza A virus subtypes (Schloer et al., 2020). S1R agonists like escitalopram and fluoxetine (Hashimoto, 2015) can prevent infection of Vero cells with vesicular stomatitis virus pseudoviral particles presenting SARS-CoV-2 spike protein (pp-VSV-SARS-CoV-2 spike) (Carpinteiro et al., 2020). Antidepressants like amitriptyline also prevented infection of human Caco-2 cells with SARS-CoV-2 and treating volunteers with a low dose of amitriptyline prevented infection of freshly isolated nasal epithelial cells with pp-VSV-SARS-CoV-2 spike (Carpinteiro et al., 2020). Inhibition of acid sphingomyelase by these drugs can prevent the conversion of sphingomyelin to phosphorylcholine and ceramide. Because high ceramide in the cell membrane facilitates viral entry, this reduction in ceramide may prevent infection (Carpenteiro et al., 2020). Therefore, functional inhibition of acid sphingomyelinase by lysosomotropic drugs is another avenue of viral control by antidepressants.

\section{Sigma-1 Receptor Activity}

S1R was discovered in 1976 (Martin et al., 1976) and cloned in 1996 (Hanner et al., 1996). It regulates ER-mitochondrial $\mathrm{Ca}^{2+}$ signaling and cell survival (Hayashi and Su 2007). Targeting S1R with FLV regulates cytokine production in human monocyte-derived dendritic cells (Szabo et al., 2014). S1R knockout (KO) bone marrow-derived macrophages (BMDMs) were proinflammatory in endotoxic shock models. They had higher levels of IL- 6 and IL- $1 \beta$ mRNA and increased IL-6 protein secretion compared to wild-type (WT) BMDMs (Rosen et al., 2019). In contrast, anti-inflammatory cytokine IL-10 expression was unaffected in S1R KO BMDMs (Rosen et al., 2019). S1R overexpression in HEKs expressing mTLR4/MD2/CD14 was antiinflammatory in an endotoxic shock model. Compared to HEKs with normal levels of S1R, cells with higher levels of S1R had lower IL-8 levels on LPS stimulation $(p<0.05)$. In other systems, FLV upregulates IL-10 (Kalkman and Feuerbach, 2016; Nazimek et al., 2017). FLV via the S1R may therefore modulate SARS-CoV-2-induced hyperinflammatory state (Figure 1).

On the flip side, genetic perturbation screens have shown depletion of S1R, decreases SARS-CoV-2 viral replication in adenocarcinoma human alveolar basal epithelial cell lines expressing Angiotensin I Converting Enzyme 2 (A549-ACE2) (Gordon et al., 2020). Consistent with this genetic data, S1R agonists such as dextromethorphan can increase viral replication (Gordon et al., 2020). However, in contrast, researchers reviewing medical billing data for nearly 740,000 COVID-19 patients in the US showed patients on antipsychotic drugs targeting S1R were half as likely as those on other types of antipsychotic drugs to require mechanical ventilation (Gordon et al., 2020).
Neurotropism is one common feature for human coronaviruses (Bale, 2015; Dube et al., 2018). Various receptors could be involved in neurotropism and neuronal cell entry of SARS-CoV-2 (Armocida et al., 2020). Sigma receptors are widely expressed in the CNS (Yesilkaya et al., 2020). Downregulation of S1R protein expression impairs initiation of hepatitis $\mathrm{C}$ virus (HCV) RNA replication in human hepatoma cells (Friesland et al., 2013). BD1047 a selective S1R antagonist blocked cocaine-mediated stimulation of human immune deficiency virus (HIV-1) expression in neuronal mononuclear phagocytes like microglia (Gekker et al., 2006). S1R could therefore be involved in neuronal transmission of other RNA viruses like SARS-CoV-2.

\section{Inositol-Requiring Enzyme 1a and Autophagy}

Endotoxin-stimulated TLR4 activates IRE1 (Martinon et al., 2010) and regulates proinflammatory cytokine production (Qiu et al., 2013). SARS-CoV E protein down-regulates IRE1 pathway and the SARS-CoV lacking the envelope (E) gene (rSARS-CoV- $\Delta \mathrm{E}$ ) is attenuated in vivo (DeDiego et al., 2011). IRE1 inhibitors like STF083010 rescued S1R KO mice in a model of endotoxemia (Rosen et al., 2019). IRE1 is essential for autophagy during infection with a gamma coronavirus-Infectious Bronchitis Virus (IBV) (Fung and Liu, 2019). SARS-CoV replicase proteins nsp2, 3 and 8 occur in cytoplasmic complexes and colocalize with LC3, a protein marker for autophagic vacuoles (Prentice et al., 2004). The viral replicase protein nsp6 of IBV activates autophagy in a screen (Cottam et al., 2011). Other studies reviewed here (Yang and Shen, 2020) suggest autophagy is not directly involved in SARS-CoV. These discrepancies are probably because of different viruses and cells tested in various studies.

\section{Melatonin}

SARS-CoV-2 virus can activate NLRP3 inflammasome (van den Berg and Te Velde, 2020), which along with NF- $\kappa$ B activation can induce cytokine storm (Ratajczak and Kucia, 2020). Melatonin can mitigate inflammation through these pathways and melatonin exposure post-intubation is associated with a positive outcome in COVID-19 (and non-COVID-19) patients (Garcia et al., 2015; Ramlall et al., 2020). FLV can elevate melatonin levels via inhibition of CYP1A2, a member of the cytochrome P450 superfamily of enzymes (Hartter et al., 2001) (Figure 1).

\section{COULD SELECTIVE SEROTONIN REUPTAKE INHIBITORS AND SIGMA-1 RECEPTOR AGONISTS HAVE DIRECT ANTIVIRAL EFFECTS ON OTHER VIRUSES?}

\section{Precedent for Using Selective Serotonin Reuptake Inhibitors to Treat Other Viral Infections}

Enteroviruses are non-enveloped RNA viruses. Their nonstructural protein $2 \mathrm{C}$ is one of their most conserved 
proteins and contains ATPase activity and putative RNA helicase activity (Cheng et al., 2013). Fluoxetine has in vitro antiviral activity against Enterovirus $B$ and $D$ species (Zuo et al., 2012; Ulferts et al., 2013). Fluoxetine binds nonstructural protein 2C directly (Manganaro et al., 2020). Some fluoxetine resistant variants of enteroviruses like coxsackievirus B3 and B4 have mutations in protein 2C (Ulferts et al., 2013; Alidjinou et al., 2019). This reinforces the idea that interaction between fluoxetine and protein $2 \mathrm{C}$ is essential for its antiviral effects.

\section{Endoplasmic Reticulum Stress Response}

Viral infection may trigger the unfolded protein response (UPR). This is an ER stress response because of ER overloading with virus-encoded proteins (Kim et al., 2008), and can also induce autophagy (Bernales et al., 2006; Ogata et al., 2006). ER signaling proteins like IRE1, PRKR-like ER kinase (PERK), and activating transcription factor 6 (ATF6) regulate UPR. The UPR is involved in viral replication and modulates host innate responses (Xue et al., 2018). Virus-induced ER stress is required for autophagy activation, viral replication, and pathogenesis in dengue (Lee et al., 2018). Murine cytomegalovirus activates the IRE1 pathway to relieve repression by X-box binding protein 1 unspliced mRNA (Hinte et al., 2020). Coronavirus infection induces ER stress and triggers UPR (Fung et al., 2016). The $S$ protein in $\beta$-coronaviruses modulates UPR to facilitate viral replication (Chan et al., 2006; Versteeg et al., 2007). The a-coronavirus, transmissible gastroenteritis virus (TGEV) triggers UPR-induced ER stress primarily through activation of PERK-eukaryotic initiation factor $2 \alpha$ axis (Xue et al., 2018). Thus ER stress response is critical in host-virus interactions in a variety of infections. We have discussed above how S1R is a regulator of IRE1 and autophagy. S1R agonists like FLV could therefore have a role in regulating viral infections beyond SARS-CoV-2 through its putative regulation of ER stress and UPR.

\section{PRECLINICAL EFFECTS OF FLUVOXAMINE ON INFLAMMATION}

S1R KO mice display increased mortality compared to WT in sublethal models of sepsis (Rosen et al., 2019). Peak serum TNF and IL-6 were increased in LPS-challenged S1R KO mice. S1R ligand FLV enhanced survival in mouse models of IRE1-mediated inflammation and fecal-induced peritonitis. FLV treatment protected WT mice from endotoxic shock-induced death, while no significant effect was observed in S1R KO animals suggesting the anti-inflammatory effects of FLV are likely mediated through S1R.

Multiple sclerosis (MS) is a chronic, inflammatory, demyelinating neurodegenerative disease. SSRIs like sertraline have been shown to have immunomodulatory effects in experimental autoimmune encephalomyelitis (EAE), a mouse model of MS (Taler et al., 2011), and in a rat model of rheumatoid arthritis (Baharav et al., 2012). FLV reduces the severity in EAE in rats, even when treatment began 12 days post-induction of EAE (Ghareghani et al., 2017). FLV-treated EAE rats showed a decrease in IFN- $\gamma$ serum levels and an increase in IL-4, pro- and anti-inflammatory cytokines respectively, compared to untreated EAE rats. The dose of FLV used in these experiments extrapolates (by surface area) to FLV doses approved for human use.

Thus, FLV seems to ameliorate inflammation in different in vivo inflammation models. Data in non-human primates or a hamster model of SARS-CoV-2 infection would shed further light on whether FLV might be a useful drug for COVID-19 patients and on the mechanism(s) at play.

\section{CLINICAL EFFECTS OF FLUVOXAMINE IN COVID-19}

In a double-blind, randomized, preliminary study of adult outpatients with symptomatic COVID-19, 80 patients treated with FLV, compared to 72 treated with placebo, had a lower likelihood of clinical deterioration over 15 days (Lenze et al., 2020). Eligible patients were enrolled within 7 days of symptom development. These data are provocative with none of the FLVtreated patients deteriorating vs. $8.3 \%$ patients in the control arm who showed clinical deterioration. Participants received $50 \mathrm{mg}$ FLV QD on day 1, then for 2 days $100 \mathrm{mg}$ FLV BID, and then $100 \mathrm{mg}$ FLV TID as tolerated through day 15 and then stopped. In a prospective study on use of FLV for early treatment of COVID-19 the incidence of hospitalization was $0 \%(0 / 65)$ with FLV and $12.5 \%(6 / 48)$ with observation alone. At 14 days, $0 \%(0 /$ 65) of FLV treated people had persistent residual symptoms compared to $60 \%(29 / 48)$ among people who opted for no therapy (Seftel and Boulware, 2021). Agonists of S1R like escitalopram and fluoxetine were associated with lower risk of intubation or death $(p<0.05)$ because of COVID-19 in a multicenter observational retrospective cohort study (Hoertel et al., 2021).

Given the multiple roles of S1R reviewed here in inflammation, platelet aggregation, antiviral activity etc. and the recent striking human data, it is likely that S1R agonists like FLV could have a major impact on disease progression of COVID-19 patients in the early stage of the disease.

\section{DISCUSSION}

An 880 patient randomized study is underway and should provide some definitive answers (Lenze, 2020). Patients nationally can join this study from home and at no cost. However, given the current crisis, which is expected to worsen before a vaccine takes effect, one wonders if the FLV evidence in COVID-19 is strong enough to consider a change in practice guidelines, to even more quickly accumulate data on outcomes in COVID-19 patients (Sukhatme and Sukhatme, 2021). A small group of healthcare systems could consider this approach and simultaneously set up tools, e.g., a local or regional repository to track outcomes in real-time. If the efficacy is similar to the small randomized trial (Lenze et al., 2020), it should be evident in such data. Out of caution, the practice guidelines could urge caregivers to consider administering FLV only to those COVID-19 
+ patients at highest risk for disease progression, and who do not have access to one of the monoclonal antibodies that have been given emergency use authorizations by the FDA (FDA, 2020a; FDA, 2020b). Also, these guidelines could be revised at any time.

Small biomarker intensive trials should be planned to assess antiviral, immunomodulatory, anti-thrombotic effects or other effects in patients treated with FLV. One could incorporate tools such as single cell RNA and protein analysis in such studies. While human data is being gathered, additional preclinical data in cell culture systems like co-cultures of human epithelial and immune cells would be useful (Grunwell et al., 2019). Data from non-human primate and hamsters would provide valuable information on optimal timing of drug, amount needed for efficacy, and which among the myriad mechanisms of action might be most relevant.

There may be a role for serotonin modulation in the inpatient setting. Indeed, if this drug is not working primarily as an antiviral but rather through other mechanisms (e.g., immunomodulatory, anti-platelet), it may be efficacious in this setting where hyperinflammatory responses and thrombotic events drive disease pathology. However, there will need to be vigilance for emergence of a hyperserotonergic state with similarities to serotonin syndrome, as noted earlier. Thus it may make sense to initiate fluvoxamine in the less severe hospitalized patients but administer a serotonin $2 \mathrm{~A}, \mathrm{~B}$ and $\mathrm{C}$ receptor antagonist such as cyproheptadine or mirtazapine in the more severe patients (along with fluvoxamine). It is also tempting

\section{REFERENCES}

Ackermann, M., Verleden, S. E., Kuehnel, M., Haverich, A., Welte, T., Laenger, F., et al. (2020). Pulmonary vascular endothelialitis, thrombosis, and angiogenesis in covid-19. N. Engl. J. Med. 383 (2), 120-128. doi:10.1056/nejmoa2015432

Alidjinou, E. K., Bertin, A., Sane, F., Caloone, D., Engelmann, I., and Hober, D. (2019). Emergence of fluoxetine-resistant variants during treatment of human pancreatic cell cultures persistently infected with coxsackievirus B4. Viruses 11 (6), 486. doi:10.3390/v11060486

Althaus, K., Marini, I., Zlamal, J., Pelzl, L., Singh, A., Häberle, H., et al. (2020). Antibody-induced procoagulant platelets in severe COVID-19 infection. Blood 137 (8), 1061-1071. doi:10.1182/blood.2020008762

Armocida, D., Palmieri, M., Frati, A., Santoro, A., and Pesce, A. (2020). How SARSCov-2 can involve the central nervous system. A systematic analysis of literature of the department of human neurosciences of Sapienza University, Italy. J. Clin. Neurosci. 79, 231-236. doi:10.1016/j.jocn.2020.07.007

Baharav, E., Bar, M., Taler, M., Gil-Ad, I., Karp, L., Weinberger, A., et al. (2012). Immunomodulatory effect of sertraline in a rat model of rheumatoid arthritis. Neuroimmunomodulation 19 (5), 309-318. doi:10.1159/000339109

Bale, J. F., Jr. (2015). Virus and immune-mediated encephalitides: epidemiology, diagnosis, treatment, and prevention. Pediatr. Neurol. 53 (1), 3-12. doi:10.1016/ j.pediatrneurol.2015.03.013

Bauer, L., Manganaro, R., Zonsics, B., Strating, J. R. P. M., El Kazzi, P., Lorenzo Lopez, M., et al. (2019). Fluoxetine inhibits enterovirus replication by targeting the viral 2C protein in a stereospecific manner. ACS Infect. Dis. 5 (9), 1609-1623. doi:10.1021/acsinfecdis.9b00179

Berger, M., Gray, J. A., and Roth, B. L. (2009). The expanded biology of serotonin. Annu. Rev. Med. 60, 355-366. doi:10.1146/annurev.med.60.042307.110802

Bernales, S., McDonald, K. L., and Walter, P. (2006). Autophagy counterbalances endoplasmic reticulum expansion during the unfolded protein response. Plos Biol. 4 (12), e423. doi:10.1371/journal.pbio.0040423

Breiden, B., and Sandhoff, K. (2019). Emerging mechanisms of drug-induced phospholipidosis. Biol. Chem. 401 (1), 31-46. doi:10.1515/hsz-2019-0270 to speculate on a role for FLV in COVID-19 long-haulers. There are likely to be subsets in this heterogeneous group that may have an aberrant immune response that has lingered on, in which FLV may be efficacious. Finally, there may be a role for FLV in the treatment of other viral illnesses in which there is some version of a cytokine storm present (Fajgenbaum and June, 2020).

\section{AUTHOR CONTRIBUTIONS}

VPS, AR, SV and VVS wrote and revised the manuscript. SV designed the figure. All authors contributed to the article and approved the submitted version.

\section{FUNDING}

Morningside Center for Innovative and Affordable Medicine at Emory University.

\section{ACKNOWLEDGMENTS}

We thank Farid Jalali for insights into COVID-19 pathology and the peripheral hyperserotonergic state that may occur due to excessive release of platelet serotonin.

Carneiro, A. M. D., Cook, E. H., Murphy, D. L., and Blakely, R. D. (2008). Interactions between integrin $\alpha \mathrm{IIb} \beta 3$ and the serotonin transporter regulate serotonin transport and platelet aggregation in mice and humans. J. Clin. Invest. 118 (4), 1544-1552. doi:10.1172/jci33374

Carpinteiro, A., Edwards, M. J., Hoffmann, M., Kochs, G., Gripp, B., Weigang, S., et al. (2020). Pharmacological inhibition of acid sphingomyelinase prevents uptake of SARS-CoV-2 by epithelial cells. Cel Rep. Med. 1 (8), 100142. doi:10. 1016/j.xcrm.2020.100142

Castano-Rodriguez, C., Honrubia, J. M., Gutierrez-Alvarez, J., DeDiego, M. L., Nieto-Torres, J. L., Jimenez-Guardeno, J. M., et al. (2018). Role of severe acute respiratory syndrome coronavirus viroporins $\mathrm{E}, 3 \mathrm{a}$, and $8 \mathrm{a}$ in replication and pathogenesis. mBio 9 (3), e02325-17. doi:10.1128/mbio.02325-17

Celada, P., Dolera, M., Alvarez, E., and Artigas, F. (1992). Effects of acute and chronic treatment with fluvoxamine on extracellular and platelet serotonin in the blood of major depressive patients. Relationship to clinical improvement. J. Affective Disord. 25 (4), 243-249. doi:10.1016/01650327(92)90082-h

Chan, C.-P., Siu, K.-L., Chin, K.-T., Yuen, K.-Y., Zheng, B., and Jin, D.-Y. (2006). Modulation of the unfolded protein response by the severe acute respiratory syndrome coronavirus spike protein. Jvi 80 (18), 9279-9287. doi:10.1128/jvi. 00659-06

Chen, G., Wu, D., Guo, W., Cao, Y., Huang, D., Wang, H., et al. (2020a). Clinical and immunological features of severe and moderate coronavirus disease 2019. J. Clin. Invest. 130 (5), 2620-2629. doi:10.1172/jci137244

Chen, N., Zhou, M., Dong, X., Qu, J., Gong, F., Han, Y., et al. (2020b). Epidemiological and clinical characteristics of 99 cases of 2019 novel coronavirus pneumonia in Wuhan, China: a descriptive study. The Lancet 395 (10223), 507-513. doi:10.1016/s0140-6736(20)30211-7

Chen, Z.-H., Xiao, L., Chen, J.-H., Luo, H.-S., Wang, G.-H., Huang, Y.-L., et al. (2008). Effects of fluoxetine on mast cell morphology and protease-1 expression in gastric antrum in a rat model of depression. Wig 14 (45), 6993-6998. doi:10. 3748/wjg.14.6993

Cheng, Z., Yang, J., Xia, H., Qiu, Y., Wang, Z., Han, Y., et al. (2013). The nonstructural protein $2 \mathrm{C}$ of a Picorna-like virus displays nucleic acid helix 
destabilizing activity that can be functionally separated from its ATPase activity. J. Virol. 87 (9), 5205-5218. doi:10.1128/jvi.00245-13

Chu, H., Chan, C.-M., Zhang, X., Wang, Y., Yuan, S., Zhou, J., et al. (2018). Middle East respiratory syndrome coronavirus and bat coronavirus HKU9 both can utilize GRP78 for attachment onto host cells. J. Biol. Chem. 293 (30), 11709-11726. doi:10.1074/jbc.ra118.001897

Cloutier, N., Allaeys, I., Marcoux, G., Machlus, K. R., Mailhot, B., Zufferey, A., et al. (2018). Platelets release pathogenic serotonin and return to circulation after immune complex-mediated sequestration. Proc. Natl. Acad. Sci. USA 115 (7), E1550-E1559. doi:10.1073/pnas.1720553115

Cottam, E. M., Maier, H. J., Manifava, M., Vaux, L. C., Chandra-Schoenfelder, P., Gerner, W., et al. (2011). Coronavirus nsp6 proteins generate autophagosomes from the endoplasmic reticulum via an omegasome intermediate. Autophagy 7 (11), 1335-1347. doi:10.4161/auto.7.11.16642

DeDiego, M. L., Nieto-Torres, J. L., Jimenez-Guardeno, J. M., Regla-Nava, J. A., Alvarez, E., Oliveros, J. C., et al. (2011). Severe acute respiratory syndrome coronavirus envelope protein regulates cell stress response and apoptosis. Plos Pathog. 7 (10), e1002315. doi:10.1371/journal.ppat.1002315

Dell'Osso, B., Allen, A., and Hollander, E. (2005). Fluvoxamine: a selective serotonin re-uptake inhibitor for the treatment of obsessive-compulsive disorder. Expert Opin. Pharmacother. 6 (15), 2727-2740. doi:10.1517/ 14656566.6.15.2727

DrugBank (2005). Fluvoxamine, December 27, 2020. from https://go.drugbank. com/drugs/DB00176.

Dube, M., Le Coupanec, A., Wong, A. H. M., Rini, J. M., Desforges, M., and Talbot, P. J. (2018). Axonal transport enables neuron-to-neuron propagation of human coronavirus OC43. J. Virol. 92 (17), e00404-18. doi:10.1128/jvi.00404-18

Duerschmied, D., Suidan, G. L., Demers, M., Herr, N., Carbo, C., Brill, A., et al. (2013). Platelet serotonin promotes the recruitment of neutrophils to sites of acute inflammation in mice. Blood 121 (6), 1008-1015. doi:10.1182/blood2012-06-437392

Fajgenbaum, D. C., and June, C. H. (2020). Cytokine storm. N. Engl. J. Med. 383 (23), 2255-2273. doi:10.1056/nejmra2026131

FDA (2012). Fluvoxamine maleate tablets label. from https://www.accessdata.fda. gov/drugsatfda_docs/label/2012/021519s003lbl.pdf (Retrieved December 27, 2020).

FDA (2020a). EUA for bamlanivimab for the treatment of mild to moderate COVID-19. from https://www.fda.gov/media/143602/download (Retrieved December 27, 2020).

FDA (2020b). EUA for casirivimab and imdevimab for the treatment of mild to moderate COVID-19. from https://www.fda.gov/media/143891/download (Retrieved December 27, 2020).

Ferjan, I., and Erjavec, F. (1996). Changes in histamine and serotonin secretion from rat peritoneal mast cells caused by antidepressants. Inflamm. Res. 45 (3), 141-144. doi:10.1007/bf02265168

Friesland, M., Mingorance, L., Chung, J., Chisari, F. V., and Gastaminza, P. (2013). Sigma-1 receptor regulates early steps of viral RNA replication at the onset of hepatitis C virus infection. J. Virol. 87 (11), 6377-6390. doi:10.1128/jvi.03557-12

Fukuda, M., Ushio, H., Kawasaki, J., Niyonsaba, F., Takeuchi, M., Baba, T., et al. (2013). Expression and functional characterization of retinoic acid-inducible gene-I-like receptors of mast cells in response to viral infection. J. Innate Immun. 5 (2), 163-173. doi:10.1159/000343895

Fung, T. S., Liao, Y., and Liu, D. X. (2016). Regulation of stress responses and translational control by coronavirus. Viruses 8 (7), 184. doi:10.3390/v8070184

Fung, T. S., and Liu, D. X. (2019). The ER stress sensor IRE1 and MAP kinase ERK modulate autophagy induction in cells infected with coronavirus infectious bronchitis virus. Virology 533, 34-44. doi:10.1016/j.virol.2019.05.002

García, J. A., Volt, H., Venegas, C., Doerrier, C., Escames, G., Acuña-Castroviejo, L. C., et al. (2015). Disruption of the NF-kB/NLRP3 connection by melatonin requires retinoid-related orphan receptor- $\alpha$ and blocks the septic response in mice. FASEB J. 29 (9), 3863-3875. doi:10.1096/fj.15-273656

Geiser, F., Conrad, R., Imbierowicz, K., Meier, C., Liedtke, R., Klingmüller, D., et al. (2011). Coagulation activation and fibrinolysis impairment are reduced in patients with anxiety and depression when medicated with serotonergic antidepressants. Psychiatry Clin. Neurosci. 65 (5), 518-525. doi:10.1111/j. 1440-1819.2011.02241.x

Gekker, G., Hu, S., Sheng, W. S., Rock, R. B., Lokensgard, J. R., and Peterson, P. K. (2006). Cocaine-induced HIV-1 expression in microglia involves sigma-1 receptors and transforming growth factor- $\beta 1$. Int. Immunopharmacology 6 (6), 1029-1033. doi:10.1016/j.intimp.2005.12.005

Ghareghani, M., Zibara, K., Sadeghi, H., Dokoohaki, S., Sadeghi, H., Aryanpour, R., et al. (2017). Fluvoxamine stimulates oligodendrogenesis of cultured neural stem cells and attenuates inflammation and demyelination in an animal model of multiple sclerosis. Sci. Rep. 7 (1), 4923. doi:10.1038/s41598-017-04968-Z

Ghosh, S., Dellibovi-Ragheb, T. A., Kerviel, A., Pak, E., Qiu, Q., Fisher, M., et al. (2020). $\beta$-Coronaviruses use lysosomes for egress instead of the biosynthetic secretory pathway. Cell 183 (6), 1520-1535. e1514. doi:10.1016/j.cell.2020. 10.039

Gordon, D. E., Hiatt, J., Bouhaddou, M., Rezelj, V. V., Ulferts, S., Braberg, H., et al. (2020). Comparative host-coronavirus protein interaction networks reveal pan-viral disease mechanisms. JScience 370 (6521), eabe9403. doi:10.1126/science.abe9403

Grunwell, J. R., Giacalone, V. D., Stephenson, S., Margaroli, C., Dobosh, B. S., Brown, M. R., et al. (2019). Neutrophil dysfunction in the airways of children with acute respiratory failure due to lower respiratory tract viral and bacterial coinfections. Sci. Rep. 9 (1), 2874. doi:10.1038/s41598-019-39726-w

Gulbins, E., Palmada, M., Reichel, M., Lüth, A., Böhmer, C., Amato, D., et al. (2013). Acid sphingomyelinase-ceramide system mediates effects of antidepressant drugs. Nat. Med. 19 (7), 934-938. doi:10.1038/nm.3214

Ha, D. P., Van Krieken, R., Carlos, A. J., and Lee, A. S. (2020). The stress-inducible molecular chaperone GRP78 as potential therapeutic target for coronavirus infection. J. Infect. 81 (3), 452-482. doi:10.1016/j.jinf.2020.06.017

Hallifax, D., and Houston, J. B. (2007). Saturable uptake of lipophilic amine drugs into isolated hepatocytes: mechanisms and consequences for quantitative clearance prediction. Drug Metab. Dispos 35 (8), 1325-1332. doi:10.1124/ dmd.107.015131

Hanner, M., Moebius, F. F., Flandorfer, A., Knaus, H. G., Striessnig, J., Kempner, E., et al. (1996). Purification, molecular cloning, and expression of the mammalian sigmal-binding site. Proc. Natl. Acad. Sci. 93 (15), 8072-8077. doi:10.1073/ pnas.93.15.8072

Härtter, S., Wang, X., Weigmann, H., Friedberg, T., Arand, M., Oesch, F., et al. (2001). Differential effects of fluvoxamine and other antidepressants on the biotransformation of melatonin. J. Clin. Psychopharmacol. 21 (2), 167-174. doi:10.1097/00004714-200104000-00008

Hashimoto, K. (2015). Activation of sigma-1 receptor chaperone in the treatment of neuropsychiatric diseases and its clinical implication. J. Pharmacol. Sci. 127 (1), 6-9. doi:10.1016/j.jphs.2014.11.010

Hashimoto, K. (2021). Repurposing of CNS drugs to treat COVID-19 infection: targeting the sigma-1 receptor. Eur. Arch. Psychiatry Clin. Neurosci. 271 (2), 249-258. doi:10.1162/2e3983f5.c37587dd

Hayashi, T., and Su, T.-P. (2007). Sigma-1 receptor chaperones at the ERmitochondrion interface regulate $\mathrm{Ca}(2+)$ signaling and cell survival. Cell 131 (3), 596-610. doi:10.1016/j.cell.2007.08.036

Helms, J., Kremer, S., Merdji, H., Clere-Jehl, R., Schenck, M., Kummerlen, C., et al. (2020a). Neurologic features in severe SARS-CoV-2 infection. N. Engl. J. Med. 382 (23), 2268-2270. doi:10.1056/nejmc2008597

Helms, J., Kremer, S., Merdji, H., Schenck, M., Severac, F., Clere-Jehl, R., et al. (2020b). Delirium and encephalopathy in severe COVID-19: a cohort analysis of ICU patients. Crit. Care 24 (1), 491. doi:10.1186/s13054-020-03200-1

Hinte, F., van Anken, E., Tirosh, B., and Brune, W. (2020). Repression of viral gene expression and replication by the unfolded protein response effector XBP1u. Elife 9, e51804. doi:10.7554/elife.51804

Hoertel, N., Sánchez-Rico, M., Vernet, R., Beeker, N., Jannot, A.-S., Neuraz, A., et al. (2021). Association between antidepressant use and reduced risk of intubation or death in hospitalized patients with COVID-19: results from an observational study. Mol. Psychiat. doi:10.1038/s41380-021-01021-4

Homolak, J., and Kodvanj, I. (2020). Widely available lysosome targeting agents should be considered as potential therapy for COVID-19. Int. J. Antimicrob. Agents 56 (2), 106044. doi:10.1016/j.ijantimicag.2020.106044

Huang, C., Wang, Y., Li, X., Ren, L., Zhao, J., Hu, Y., et al. (2020). Clinical features of patients infected with 2019 novel coronavirus in Wuhan, China. The Lancet 395 (10223), 497-506. doi:10.1016/s0140-6736(20)30183-5

Irons, J. (2005). Fluvoxamine in the treatment of anxiety disorders. Neuropsychiatr. Dis. Treat. 1 (4), 289-299.

Ishima, T., Fujita, Y., and Hashimoto, K. (2014). Interaction of new antidepressants with sigma-1 receptor chaperones and their potentiation of neurite outgrowth in PC12 cells. Eur. J. Pharmacol. 727, 167-173. doi:10.1016/j.ejphar.2014.01.064 
Javors, M. A., Houston, J. P., Tekell, J. L., Brannan, S. K., and Frazer, A. (2000). Reduction of platelet serotonin content in depressed patients treated with either paroxetine or desipramine. Int. J. Neuropsychopharm. 3 (3), 229-235. doi:10. 1017/s146114570000198x

Joseph, D., Puttaswamy, R. K., and Krovvidi, H. (2013). Non-respiratory functions of the lung. Continuing Educ. Anaesth. Crit. Care Pain 13 (3), 98-102. doi:10. 1093/bjaceaccp/mks060

Kalkman, H. O., and Feuerbach, D. (2016). Antidepressant therapies inhibit inflammation and microglial M1-polarization. Pharmacol. Ther. 163, 82-93. doi:10.1016/j.pharmthera.2016.04.001

Kazmi, F., Hensley, T., Pope, C., Funk, R. S., Loewen, G. J., Buckley, D. B., et al. (2013). Lysosomal sequestration (trapping) of lipophilic amine (cationic amphiphilic) drugs in immortalized human hepatocytes (Fa2N-4 cells). Drug Metab. Dispos 41 (4), 897-905. doi:10.1124/dmd.112.050054

Kim, I., Xu, W., and Reed, J. C. (2008). Cell death and endoplasmic reticulum stress: disease relevance and therapeutic opportunities. Nat. Rev. Drug Discov. 7 (12), 1013-1030. doi:10.1038/nrd2755

Kornhuber, J., Tripal, P., Reichel, M., Terfloth, L., Bleich, S., Wiltfang, J., et al. (2008). Identification of new functional inhibitors of acid sphingomyelinase using a Structure-Property-Activity relation model. J. Med. Chem. 51 (2), 219-237. doi:10.1021/jm070524a

Lee, Y. R., Kuo, S. H., Lin, C. Y., Fu, P. J., Lin, Y. S., Yeh, T. M., et al. (2018). Dengue virus-induced ER stress is required for autophagy activation, viral replication, and pathogenesis both in vitro and in vivo. Sci. Rep. 8 (1), 489. doi:10.1038/ s41598-017-18909-3

Lenze, E. (2020). Fluvoxamine for early treatment of covid-19 (stop covid 2).from https://clinicaltrials.gov/ct2/show/NCT04668950. (Retrieved December 27, 2020).

Lenze, E. J., Mattar, C., Zorumski, C. F., Stevens, A., Schweiger, J., Nicol, G. E., et al. (2020). Fluvoxamine vs placebo and clinical deterioration in outpatients with symptomatic COVID-19. JAMA 324 (22), 2292-2300. doi:10.1001/jama.2020. 22760

Leung, M., and Shore, R. (1996). Fluvoxamine-associated bleeding. Can. J. Psychiatry 41 (9), 604-605. doi:10.1177/070674379604100919

Lu, W., Zheng, B.-J., Xu, K., Schwarz, W., Du, L., Wong, C. K. L., et al. (2006). Severe acute respiratory syndrome-associated coronavirus 3a protein forms an ion channel and modulates virus release. Proc. Natl. Acad. Sci. 103 (33), 12540-12545. doi:10.1073/pnas.0605402103

Manganaro, R., Zonsics, B., Bauer, L., Lorenzo Lopez, M., Donselaar, T., Zwaagstra, M., et al. (2020). Synthesis and antiviral effect of novel fluoxetine analogues as enterovirus 2C inhibitors. Antiviral Res. 178, 104781. doi:10.1016/j.antiviral.2020.104781

Martin, W. R., Eades, C. G., Thompson, J. A., Huppler, R. E., and Gilbert, P. E. (1976). The effects of morphine- and nalorphine- like drugs in the nondependent and morphine-dependent chronic spinal dog. J. Pharmacol. Exp. Ther. 197 (3), 517-532.

Martinon, F., Chen, X., Lee, A.-H., and Glimcher, L. H. (2010). TLR activation of the transcription factor XBP1 regulates innate immune responses in macrophages. Nat. Immunol. 11 (5), 411-418. doi:10.1038/ni.1857

McCloskey, D. J., Postolache, T. T., Vittone, B. J., Nghiem, K. L., Monsale, J. L., Wesley, R. A., et al. (2008). Selective serotonin reuptake inhibitors: measurement of effect on platelet function. Translational Res. 151 (3), 168-172. doi:10.1016/j.trsl.2007.10.004

Motta Junior, J. D. S., Miggiolaro, A., Nagashima, S., de Paula, C. B. V., Baena, C. P., Scharfstein, J., et al. (2020). Mast cells in alveolar septa of COVID-19 patients: a pathogenic pathway that may link interstitial edema to immunothrombosis. Front. Immunol. 11, 574862. doi:10.3389/fimmu.2020.574862

Naji Esfahani, H., Rafiee, L., and Haghjooy Javanmard, S. (2019). Evaluation of the effect of antidepressant drug, fluvoxamine, on cyclooxygenase-2 protein expression in lipopolysaccharide-stimulated macrophages. Adv. Biomed. Res. 8, 5. doi:10.4103/abr.abr_141_18

Narayan, M., Cellar, J., Mallison, R. T., Price, L. H., Nelson, J. C., and Nelson, J. C. (1998). Serotonin transporter-blocking properties of nefazodone assessed by measurement of platelet serotonin. J. Clin. Psychopharmacol. 18 (1), 67-71. doi:10.1097/00004714-199802000-00011

Narita, N., Hashimoto, K., Tomitaka, S.-i., and Minabe, Y. (1996). Interactions of selective serotonin reuptake inhibitors with subtypes of $\sigma$ receptors in rat brain. Eur. J. Pharmacol. 307 (1), 117-119. doi:10.1016/0014-2999(96)00254-3

Nazimek, K., Strobel, S., Bryniarski, P., Kozlowski, M., Filipczak-Bryniarska, I., and Bryniarski, K. (2017). The role of macrophages in anti-inflammatory activity of antidepressant drugs. Immunobiology 222 (6), 823-830. doi:10.1016/j.imbio. 2016.07.001

Nazy, I., Jevtic, S. D., Moore, J. C., Huynh, A., Smith, J. W., Kelton, J. G., et al. (2021). Platelet-activating immune complexes identified in critically ill COVID19 patients suspected of heparin-induced thrombocytopenia. J. Thromb. Haemost. doi: $10.1111 /$ jth. 15283

NHLBI (2020). NIH ACTIV trial of blood thinners pauses enrollment of critically ill COVID-19 patients. from https://www.nhlbi.nih.gov/news/2020/nih-activ-trialblood-thinners-pauses-enrollment-critically-ill-covid-19-patients (Retrieved December 27, 2020)

Ni, W., and Watts, S. W. (2006). 5-hydroxytryptamine in the cardiovascular system: focus on the serotonin transporter (SERT). Clin. Exp. Pharmacol. Physiol. 33 (7), 575-583. doi:10.1111/j.1440-1681.2006.04410.x

Nishimura, T., Ishima, T., Iyo, M., and Hashimoto, K. (2008). Potentiation of nerve growth factor-induced neurite outgrowth by fluvoxamine: role of sigma-1 receptors, IP3 receptors and cellular signaling pathways. PLoS One 3 (7), e2558. doi:10.1371/journal.pone.0002558

Ogata, M., Hino, S.-i., Saito, A., Morikawa, K., Kondo, S., Kanemoto, S., et al. (2006). Autophagy is activated for cell survival after endoplasmic ReticulumStress. Mcb 26 (24), 9220-9231. doi:10.1128/mcb.01453-06

Prentice, E., McAuliffe, J., Lu, X., Subbarao, K., and Denison, M. R. (2004). Identification and characterization of severe acute respiratory syndrome coronavirus replicase proteins. Jvi 78 (18), 9977-9986. doi:10.1128/jvi.78.18. 9977-9986.2004

Qiu, Q., Zheng, Z., Chang, L., Zhao, Y.-S., Tan, C., Dandekar, A., et al. (2013). Tolllike receptor-mediated IRE1a activation as a therapeutic target for inflammatory arthritis. EMBO J. 32 (18), 2477-2490. doi:10.1038/emboj. 2013.183

Rafiee, L., Hajhashemi, V., and Javanmard, S. H. (2016). Fluvoxamine inhibits some inflammatory genes expression in LPS/stimulated human endothelial cells, U937 macrophages, and carrageenan-induced paw edema in rat. Iran J. Basic Med. Sci. 19 (9), 977-984. doi:10.22038/ ijbms.2016.7598

Ramlall, V., Zucker, J., and Tatonetti, N. (2020). Melatonin is significantly associated with survival of intubated COVID-19 patients. medRxiv. doi:10. $1101 / 2020.10 .15 .20213546$

Ratajczak, M. Z., and Kucia, M. (2020). SARS-CoV-2 infection and overactivation of Nlrp3 inflammasome as a trigger of cytokine "storm" and risk factor for damage of hematopoietic stem cells. Leukemia 34 (7), 1726-1729. doi:10.1038/ s41375-020-0887-9

Rosen, D. A., Seki, S. M., Fernandez-Castaneda, A., Beiter, R. M., Eccles, J. D., Woodfolk, J. A., et al. (2019). Modulation of the sigma-1 receptor-IRE1 pathway is beneficial in preclinical models of inflammation and sepsis. Sci. Transl Med. 11 (478), eaau5266. doi:10.1126/scitranslmed.aau5266

Schloer, S., Brunotte, L., Goretzko, J., Mecate-Zambrano, A., Korthals, N., Gerke, V., et al. (2020). Targeting the endolysosomal host-SARS-CoV-2 interface by clinically licensed functional inhibitors of acid sphingomyelinase (FIASMA) including the antidepressant fluoxetine. Emerging Microbes \& Infections 9 (1), 2245-2255. doi:10.1080/22221751.2020.1829082

Seftel, D., and Boulware, D. R. (2021). Prospective cohort of fluvoxamine for early treatment of COVID-19. Open Forum Infect. Dis. 8 (2), ofab050. doi:10.1093/ ofid/ofab050

Sukhatme, V., and Sukhatme, V. (2021). A call to action: immediate deployment of select repurposed drugs for COVID-19 outpatient treatment. February 12, 2021, 2021. from https://www.healthaffairs.org/do/10.1377/hblog20210208.174907/full/.

Sundstrom, J. B., Little, D. M., Villinger, F., Ellis, J. E., and Ansari, A. A. (2004). Signaling through Toll-like receptors triggers HIV-1 replication in latently infected mast cells. J. Immunol. 172 (7), 4391-4401. doi:10.4049/jimmunol.172. 7.4391

Szabo, A., Kovacs, A., Frecska, E., and Rajnavolgyi, E. (2014). Psychedelic N,Ndimethyltryptamine and 5-methoxy-N,N-dimethyltryptamine modulate innate and adaptive inflammatory responses through the sigma-1 receptor of human monocyte-derived dendritic cells. PLoS One 9 (8), e106533. doi:10.1371/journal. pone. 0106533

Taler, M., Gil-Ad, I., Korob, I., and Weizman, A. (2011). The immunomodulatory effect of the antidepressant sertraline in an experimental autoimmune encephalomyelitis mouse model of multiple sclerosis. Neuroimmunomodulation 18 (2), 117-122. doi:10.1159/000321634 
Taler, M., Gil-Ad, I., Lomnitski, L., Korov, I., Baharav, E., Bar, M., et al. (2007). Immunomodulatory effect of selective serotonin reuptake inhibitors (SSRIs) on human $\mathrm{T}$ lymphocyte function and gene expression. Eur. Neuropsychopharmacol. 17 (12), 774-780. doi:10.1016/j.euroneuro.2007.03.010

Tay, M. Z., Poh, C. M., Rénia, L., MacAry, P. A., and Ng, L. F. P. (2020). The trinity of COVID-19: immunity, inflammation and intervention. Nat. Rev. Immunol. 20 (6), 363-374. doi:10.1038/s41577-020-0311-8

Theoharides, T. C. (2020). COVID -19, pulmonary mast cells, cytokine storms, and beneficial actions of luteolin. Biofactors 46 (3), 306-308. doi:10.1002/biof.1633

Thomas, D. P., and Vane, J. R. (1967). 5-hydroxytryptamine in the circulation of the dog. Nature 216 (5113), 335-338. doi:10.1038/216335a0

Tynan, R. J., Weidenhofer, J., Hinwood, M., Cairns, M. J., Day, T. A., and Walker, F. R. (2012). A comparative examination of the anti-inflammatory effects of SSRI and SNRI antidepressants on LPS stimulated microglia. Brain Behav. Immun. 26 (3), 469-479. doi:10.1016/j.bbi.2011.12.011

Ulferts, R., van der Linden, L., Thibaut, H. J., Lanke, K. H. W., Leyssen, P., Coutard, B., et al. (2013). Selective serotonin reuptake inhibitor fluoxetine inhibits replication of human enteroviruses $\mathrm{B}$ and $\mathrm{D}$ by targeting viral protein $2 \mathrm{C}$. Antimicrob. Agents Chemother. 57 (4), 1952-1956. doi:10.1128/aac.02084-12

van den Berg, D. F., and Te Velde, A. A. (2020). Severe COVID-19: NLRP3 inflammasome dysregulated. Front. Immunol. 11, 1580. doi:10.3389/fimmu. 2020.01580

Vanhoutte, P. M. (1991). Platelet-derived serotonin, the endothelium, and cardiovascular disease. J. Cardiovasc. Pharmacol. 17 (Suppl. 5), S13-S12. doi:10.1097/00005344-199100175-00003

Vela, J. M. (2020). Repurposing sigma-1 receptor ligands for COVID-19 therapy? Front. Pharmacol. 11, 582310. doi:10.3389/fphar.2020.582310

Versteeg, G. A., van de Nes, P. S., Bredenbeek, P. J., and Spaan, W. J. M. (2007). The coronavirus spike protein induces endoplasmic reticulum stress and upregulation of intracellular chemokine mRNA concentrations. J. Virol. 81 (20), 10981-10990. doi:10.1128/jvi.01033-07

Wang, Z., Lai, Y., Bernard, J. J., Macleod, D. T., Cogen, A. L., Moss, B., et al. (2012). Skin mast cells protect mice against vaccinia virus by triggering mast cell receptor S1PR2 and releasing antimicrobial peptides. J.I. 188 (1), 345-357. doi:10.4049/jimmunol.1101703

Wishart, D. S., Feunang, Y. D., Guo, A. C., Lo, E. J., Marcu, A., Grant, J. R., et al. (2018). DrugBank 5.0: a major update to the DrugBank database for 2018. Nucleic Acids Res. 46 (D1), D1074-D1082. doi:10.1093/nar/gkx1037
Xue, M., Fu, F., Ma, Y., Zhang, X., Li, L., Feng, L., et al. (2018). The PERK arm of the unfolded protein response negatively regulates transmissible gastroenteritis virus replication by suppressing protein translation and promoting type I interferon production. J. Virol. 92 (15), e00431-18. doi:10.1128/jvi.00431-18

Yang, N., and Shen, H.-M. (2020). Targeting the endocytic pathway and autophagy process as a novel therapeutic strategy in COVID-19. Int. J. Biol. Sci. 16 (10), 1724-1731. doi:10.7150/ijbs.45498

Yesilkaya, U. H., Balcioglu, Y.H., and Sahin, S. (2020). Reissuing the sigma receptors for SARS-CoV-2. J. Clin. Neurosci. 80, 72-73. doi:10.1016/j.jocn.2020.08.014

Yue, Y., Nabar, N. R., Shi, C. S., Kamenyeva, O., Xiao, X., Hwang, I. Y., et al. (2018). SARS-Coronavirus Open Reading Frame-3a drives multimodal necrotic cell death. Cell Death Dis 9 (9), 904. doi:10.1038/s41419-018-0917-y

Zaid, Y., Guessous, F., Puhm, F., Elhamdani, W., Chentoufi, L., Morris, A. C., et al. (2021). Platelet reactivity to thrombin differs between patients with COVID-19 and those with ARDS unrelated to COVID-19. Blood Adv. 5 (3), 635-639. doi:10.1182/bloodadvances.2020003513

Zuo, J., Quinn, K. K., Kye, S., Cooper, P., Damoiseaux, R., and Krogstad, P. (2012). Fluoxetine is a potent inhibitor of coxsackievirus replication. Antimicrob. Agents Chemother. 56 (9), 4838-4844. doi:10.1128/aac.00983-12

Conflict of Interest: Author VVS was employed by the company GlobalCures, Inc. Author AR has received research support for clinical trials of fluvoxamine for COVID-19 from the Taylor Family Institute for Innovative Psychiatric Treatment at Washington University, Fast Grants, and the COVID-19 Early Treatment Fund, and she is an inventor on a patent application filed by Washington University in St. Louis, which is relevant to methods of treating COVID-19, including fluvoxamine.

The remaining authors declare that the research was conducted in the absence of any commercial or financial relationships that could be construed as a potential conflict of interest.

Copyright (c) 2021 Sukhatme, Reiersen, Vayttaden and Sukhatme. This is an openaccess article distributed under the terms of the Creative Commons Attribution License (CC BY). The use, distribution or reproduction in other forums is permitted, provided the original author(s) and the copyright owner(s) are credited and that the original publication in this journal is cited, in accordance with accepted academic practice. No use, distribution or reproduction is permitted which does not comply with these terms. 